\title{
Stereotactic body radiation therapy for abdominal oligometastases: a biological and clinical review
}

\author{
Mohammed Yahia Almaghrabi', Stéphane Supiot ${ }^{1,2}$, Francois Paris ${ }^{2}$, Marc-André Mahé ${ }^{1}$ and Emmanuel Rio ${ }^{\text {** }}$
}

\begin{abstract}
Advances in imaging and biological targeting have led to the development of stereotactic body radiation therapy (SBRT) as an alternative treatment of extracranial oligometastases. New radiobiological concepts, such as ceramide-induced endothelial apoptosis after hypofractionated high-dose SBRT, and the identification of patients with oligometastatic disease by microRNA expression may yet lead to further developments. Key factors in SBRT are delivery of a high dose per fraction, proper patient positioning, target localisation, and management of breathingrelated motion. Our review addresses the radiation doses and schedules used to treat liver, abdominal lymph node $(\mathrm{LN})$ and adrenal gland oligometastases and treatment outcomes. Reported local control (LC) rates for liver and abdominal LN oligometastases are high (median 2-year actuarial LC: 61 -100\% for liver oligometastases; 4-year actuarial LC: $68 \%$ in a study of abdominal LN oligometastases). Early toxicity is low-to-moderate; late adverse effects are rare. SBRT of adrenal gland oligometastases shows promising results in the case of isolated lesions. In conclusion, properly conducted SBRT procedures are a safe and effective treatment option for abdominal oligometastases.
\end{abstract}

Keywords: Cancer, Gastrointestinal, Liver, Radiotherapy, Radiation biology, Surgery

\section{Introduction}

Stereotactic Body Radiation Therapy (SBRT) was developed in the wake of Intracranial Stereotactic Radiosurgery (SRS) and Fractionated Stereotactic Radiotherapy (SRT) as a result of technological advances made in the early 1990's in tumour motion quantification and image guidance [1]. Stereotaxy is a form of neurosurgery that uses a mechanical head frame and a precise 3-dimensional (3D) coordinate system to align and direct surgical instruments. SRT uses the methods of stereotactic neurosurgery to locate and target malignant and benign brain lesions before the delivery of radiation therapy [2].

In 1994, Lax et al. in Sweden applied this 3D approach to the targeting of extracranialtumours [3]. They constructed a combined body frame-abdominal compressing device and devised a method for the placement of external fiducial markers that could be indexed to the internal target. In 1998, Uematsu et al. developed a frameless "focal unit" which combines a

\footnotetext{
* Correspondence: emmanuel.rio@ico.unicancer.fr

'Department of Radiation Oncology, Integrated Oncology Centre, BD du

Professeur Jacques MONOD, 44805, Saint-Herblain, France

Full list of author information is available at the end of the article
}

linear accelerator (Linac), computed tomography (CT) scanner, and X-ray simulator (X-S) [4]. Treatment of 66 primary and metastatic lung carcinomas by this technique resulted in only 2 cases of local progression.

SBRT is a superior "focal unit" combining hypofractionated multi-beam conformal radiotherapy (CRT) and image-guided radiotherapy (IGRT). It delivers a high radiation dose, divided into several fractions ("hypofractionated"), to extracranial lesions. It is a high- precision technique with tight planning margins and a sophisticated treatment plan allowing rapid dose fall-off away from the treatment area. It provides improved volume targeting and smaller irradiated volumes of normal tissue. Its use is usually limited to well-circumscribed tumours (maximum cross-sectional diameter of up to $5 \mathrm{~cm}$ ) but tumours as large as $7 \mathrm{~cm}$ have been treated. Low isodoses (e.g. $80 \%$ isodose) are often prescribed due to dose heterogeneity within the target [5]. Its exact definition can, however, vary.

SBRT use was initially confined to patients with unresectable or medically inoperable tumours. Nowadays, however, its use has been extended to patients with resectable or medically operable tumours. Results are encouraging in the treatment of lung and liver metastases but

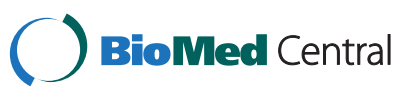


less clear-cut in the treatment of abdominal lymph node (LN) and adrenal gland. Provided that dosimetric constraints are met, SBRT is well tolerated.

Oligometastases are metastases that are limited in number and location. Hellman and Weichselbaum coined this term in 1995 [6]. They hypothesised that patients with less aggressive tumours and few new metastases during the first 4 months of first metastatic progression could potentially benefit from metastasis-directed therapy. They also identified a class of small RNAs, known as microRNAs, which might help distinguish patients with stable oligometastatic disease from patients with progression to polymetastatic disease. Oligometastases produced by early progression of primary lesions are known as de novo "oligometastases" whereas widespread metastases correspond to a state of "induced oligometastases" [7].

The aim of SBRT is to achieve good local control (LC) of each oligometastatic site and possibly the cure of some patients. Careful patient selection is needed. The best candidates for SBRT are patients with controlled primary tumours (colon or breast, sarcomas, kidney carcinomas), 4 or fewer oligometastatic sites, oligometastases $<5 \mathrm{~cm}$, younger age, and good performance status [1].

This review will present the emerging role of hypofractionated SBRT in treating oligometastases to abdominal organs and lymph nodes.

\section{Biology of hypofractionated SBRT and oligometastases}

Experimental work has suggested that the greater efficacy of hypofractionated high-dose SBRT over normofractionated RT in the treatment of radioresistanttumours might be due to different effects on both tumour and normal cells.

Radiation-induced cell death has been modelled according to the linear-quadratic (LQ) model which postulates that multiple radioinduced lesions interact in the cell to trigger cell killing. This assumption is described by the equation: $\mathrm{S}=\mathrm{e}-(\mathrm{aD}+\mathrm{bD} 2)$. The model is widely used in RT to calculate isoeffect doses for different.

According to the LQ model, high-dose fractions are needed to enhance tumour cell death. Treatment planning margins must therefore be small in order to reduce the total volume of normal tissue within the radiation field and to minimise late adverse effects, and the interval between fractions must enable complete repair of normal tissues. The LQ model is a reliable and mechanistically plausible model for designing protocols in the 2-10 Gy dose per fraction range. A loss in accuracy is expected above 10 Gy but, according to animal data, the model remains acceptable for designing clinical trials up to a 15-18 Gy dose per fraction [8].

The concepts underlying the damaging effects of ionising radiation on normal tissue architecture were introduced in the 1980's $[9,10]$. Basically, organs are divided into two types according to their response to RT: (i) parallel functioning organs are made up of functional subunits that act independently (lung, liver, kidneys, and glandular tissues beyond the major ducts); (ii) serial functioning organs are made up of functional subunits that act in cooperation (bowels, bronchi, large ducts in glands, blood vessels, and nerves). SBRT can cause profound late adverse effects if delivered near serially functioning tissues [1].

The biologically most significant mechanism underlying radiation-induced damage in tumours and normal tissue is generally thought to be clonogenic cell death due to radioinduced DNA double-strand breaks (DSBs). Recently, however, ceramide-induced endothelial apoptosis rather than DNA DSB-induced clonogenic cell death has been considered to underlie the effects of hypofractionated SBRT [11]. Protection of endothelial cells against apoptosis induced by exposure to clinically relevant radiation doses is given by basic fibroblast growth factor (bFGF), and this natural protection mechanism may be associated with radiation resistance in normal and malignant tissues in vivo [12]. An immune-mediated mechanism might also contribute toward better survival outcomes for SBRT than conventional RT.

Experimental work has shown that ablative RT (15$25 \mathrm{~Gy} \times 1$ ) alone generates strong enough $\mathrm{CD} 8+\mathrm{T}$ cell-dependent immunity to lead to tumour reduction, reduced relapse of primary tumour, and even eradication of metastasis in some settings [13], thus bringing current intensive RT/chemotherapy protocols into question. Finally, microRNAs may play a key role. A study of 42 tumour samples from oligometastatic patients treated with high-dose RT found that microRNA-200c expression enhancement in an oligometastatic cell-line resulted in polymetastatic progression [14]. The radiobiology of high-dose RT delivered to oligometastases is a field of intensive study.

\section{The SBRT procedure}

SBRT has to overcome four hurdles: (i) patient positioning, (ii) internal organ motion, (iii) target volume shrinkage or expansion and (iv) subclinical malignant involvement not identifiable on the images available at treatment planning [15]. Proper patient positioning, target localisation, and management of breathing-related motion are essential to ensure the tight planning margins of SBRT. SBRT uses a wide variety of imaging techniques to delineate lesions and in dose calculations, of patient immobilisation and positioning devices to ensure safety and reliability, and of image guidance systems (Table 1) [5,16]. Recent SBRT-ready machines integrate several state-of-the-art RT capabilities (IGRT and immobilisation and respiratory motion solution technology) into a single machine. 
Table 1 Components of SBRT

\begin{tabular}{|c|c|}
\hline Component & Some examples \\
\hline Imaging & $\begin{array}{l}\text { General radiography; 3- or 4-Dimensional Computed Tomography (CT); Magnetic } \\
\text { Resonance Imaging (MRI); Magnetic Resonance Spectroscopy (MRS); Positron Emission } \\
\text { Tomography (PET) with or without image fusion with other techniques }\end{array}$ \\
\hline Patient immobilisation and positioning & Stereotactic Body Frame ${ }^{\mathrm{TM}}$ (Elekta, USA); BodyFix ${ }^{\mathrm{TM}}$ (Medical Intelligence, Germany) \\
\hline Image guidance & 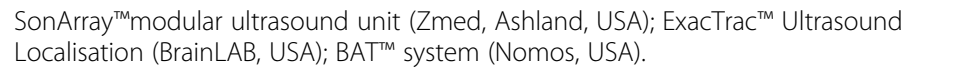 \\
\hline SBRT-ready machines & 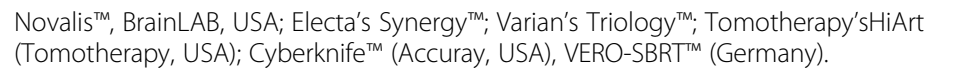 \\
\hline
\end{tabular}

On completion of pretreatment simulation, the Gross Tumour Volume (GTV) is outlined in each slice where the lesion appears. A Clinical Target Volume (CTV) is applied to account for microscopic extension of the lesion although, in the case of metastases, the CTV and GTV are considered equal. The final Planning Target Volume (PTV) has even larger margins $(\leq 10 \mathrm{~mm})$ in order to correct for inaccuracies in the delivery system $[17,18]$. In general the PTV is encompassed by the $65-95 \%$ isodose line. SBRT may use a single treatment fraction ("radiosurgery") or up to 10 fractions ("hypofractionated" SBRT).

Most reports on SBRT delivered by a gantry-operated linear accelerator mention the use of a method of motion management at planning and/or treatment. A variety of methods are used: (i) addition of constraints to the immobilisation device (e.g. dual vacuum technology for Medical Intelligence's BodyFix ${ }^{\mathrm{xm}}$, a diaphragm control device for Elekta's Stereotactic Body Frame ${ }^{\mathrm{Tm}}$ ), (ii) use of tracking devices with fiducial markers implanted near the target volume (e.g. Cyberknife ${ }^{\mathrm{Ta}}$, BrainLabExacTrac ${ }^{\mathrm{Tm}}$ ), (iii) Gated Radiotherapy (GRT). Internal fiducial markers are used to track tumour motion in real-time during treatment but can cause artefacts on the images used for treatment planning. Although SBRT is considered to be non-invasive, these markers are implanted percutaneously under CT- or ultrasound-guidance. Their purpose is to reduce internal organ motion to $<5 \mathrm{~mm}$.

The efficacy of GRT was first established on treatment of tumours located close to the diaphragm [19]. In GRT, devices that monitor breathing trigger radiation delivery during specific phases of the respiratory cycle, or the radiation beam is continuously turned on and off to synchronize delivery with the respiration cycle. Patients can breathe freely (e.g. Varian's Real-time Position Management $^{\text {mix }}$ (RPM) system) or a pause in breathing can be induced either by an occlusion valve operated by the clinician (e.g. Elekta's Active Breathing Coordinator ${ }^{\text {th }}$ $(\mathrm{ABC})$ ) or voluntarily by the patients themselves (deep inspiratory breath hold (SpiroDynr' ${ }^{\mathrm{sm}}$, France). A breath-hold device is used with single-shot echo-planarimaging (EPI) but also with other types of IGRT such as 3D-CBCT.
Geometrical uncertainties, which can be machine related (e.g. laser misalignment) or patient related (e.g. target volume definition, setup errors, organ motion), are handled by applying safety margins (Table 2) [20-25]. In addition, basing nodal RT portals on vascular rather than bony anatomy can significantly reduce normal tissue irradiation [26]. IGRT enables automatic correction of patient position through translation and rotation of the treatment couch on based measurements provided by the imaging system [27]. The most common image guidance system used to obtain volumetric information on patient geometry is 3D-cone-beam-CT (CBCT). It has become standard equipment on many modern linear accelerators.

Biological image-guidance and dose-painting are two developments that have been combined with SBRT to customise treatment. However, they have not yet been validated for SBRT of oligometastases. Ling et al. hypothesised that "biological" images revealing metabolic, functional, and physiological activity can be used to derive a biological target volume (BTV) in order to incrementally improve target delineation and dose delivery [28]. For example, image fusion between MRI and FDG-PET/CT in a simulator is used to identify hypermetabolic activity areas and microscopic disease extension. MRI tends to be used for imaging of liver oligometastases and PET for imaging of abdominal LN and adrenal oligometastases. Fluoro-D-glucose (FDG)$\mathrm{PET} / \mathrm{CT}$ use is hampered, in the case of liver oligometastases, by breathing-related motion and physiological FDG uptake by the liver and, in the case of abdominal oligometastases, by peristalsis movements of the intestine. Dose-painting radiotherapy (DPRT), which makes use of PET-CT with tracers other than FDG (fluoromisomidazole (Fmiso) or fluroro-L-thymidine (FLT)) or dynamic contrast enhanced (DCE)-MRI, delivers a higher dose to the most radioresistant areas of the tumour and reduces the dose to the most sensitive areas [29].

Although practice guidelines on SBRT have been issued by the American Society for Therapeutic Radiology and Oncology (ASTRO) and the American College of Radiology (ACR), wide variations persist among centers in prescription patterns and treatment delivery systems [16]. 
Table 2 Advocated safety margins

\begin{tabular}{|c|c|c|}
\hline Team & Metastases & Recommendation \\
\hline \multirow[t]{4}{*}{ Schefter et al. 2005 [20] } & SBRT of liver metastases & Minimum distance between GTV and PTV surfaces: \\
\hline & & — $0.5 \mathrm{~cm}$, axial planes \\
\hline & & $-1.0 \mathrm{~cm}$, superior/inferior \\
\hline & & Cumulative maximum tumourdiameter: $<6 \mathrm{~cm}$ \\
\hline \multirow[t]{4}{*}{ Katria et al. 2010 [21] } & IGRT of abdomen and pelvis & Stroom's and Van Herk's margins (cm): \\
\hline & & — 0.39 and $0.35 \mathrm{~mm}$, anterior-posterior \\
\hline & & - 0.94 and $0.46 \mathrm{~mm}$, medial-lateral \\
\hline & & - 0.40 and $1.09 \mathrm{~mm}$, superior-inferior \\
\hline Wysocka et al. 2010 [22] & & $\begin{array}{l}\text { Median } 3.8 \mathrm{~mm} \text { intrafraction craniocaudal displacement } \\
\text { for coeliac axis with smaller displacements for other axes }\end{array}$ \\
\hline RTOG consensus guidelines [23] & Inguinal lymph nodes & $\begin{array}{l}\text { Caudad extent of the inguinal region: } 2 \mathrm{~cm} \text { to the } \\
\text { saphenous/femoral junction }\end{array}$ \\
\hline Kim et al. 2011 [24] & Inguinal and femoral nodes & $2.2-2.9 \mathrm{~cm}$ around femoral vessels \\
\hline \multirow[t]{4}{*}{ Van Weieringen et al. 2011 [25] } & Pelvic lymph nodes & For offline and online correction protocols, respectively: \\
\hline & & -7 and $5 \mathrm{~mm}$, left-right \\
\hline & & - 6 and $5 \mathrm{~mm}$,craniocaudal \\
\hline & & - 8 and $7 \mathrm{~mm}$,dorsoventral \\
\hline
\end{tabular}

RTOG: Radiation Therapy Oncology Group.

\section{Methodology of systematic review of clinical trials on SBRT of oligometastases}

Most published work on SBRT use in oligometastatic abdominal disease concerns liver metastases rather than abdominal lymph nodes or adrenal gland metastases.

The following summary of clinical trials is based on a systematic Medline search (languages: English \& French; key-words: "stereotactic", "radiotherapy", "cancer: metastases, oligometastases", "liver", "abdominal lymph nodes", "adrenal gland", "extracranial”, "surgery"; publication types: original articles and reviews; dates: 1995 to Nov 2010; updated in Mar. 2012 and of a manual search of cited references, selected journals, and abstracts of international congresses (ESTRO2010, ASTRO2010 and ASTRO2011). Preferential article selection criteria were as follows: (i) for SBRT of liver metastases: prospective trials reporting actuarial local control (LC) in $\geq 20$ lesions after treatment with $\leq 5$ SBRT fractions, as well as trials on primary liver cancer and oligometastases, (ii) for SBRT of abdominal LN and adrenal gland metastases: all available prospective and retrospective studies trials. Because of marked variations in the reporting of doses and outcomes among studies, a unified analysis was not possible.

\section{SBRT of liver oligometastases}

The liver is a common metastatic site for a variety of primary malignancies including colorectal, lung, breast, bladder, oesophageal, head \& neck and pancreatic cancers, and cholangiocarcinoma. According to the most recent version of the National Comprehensive Cancer Network (NCCN) guidelines (v.3.2012), surgical resection is still the standard of care for liver metastases. However, despite the favourable outcomes that have been reported after surgery [30,31], 80-90\% of patients are either patients with lesions that are surgically not resectable or are medically inoperable patients at the time of diagnosis [32].

The first radiotherapeutic modality used to treat liver metastases was Whole Liver RT (WLRT) [33]. Results were encouraging but radiotherapy regimens of 32 Gy in 16 fractions or more were insufficient to eradicate disease and were often associated with radiation-induced liver disease (RILD). RILD is a clinical syndrome of anicteric hepatomegaly, ascites, and elevated liver enzymes occurring within 3 months after completion of therapy. Attempts to increase the efficacy of WLRT proved unsatisfactory [34] and led to the development of Partial Liver Radiation Therapy (PLRT). Low-dose WLRT nevertheless remains a useful treatment for symptom palliation in patients with end-stage cancer and diffuse metastatic infiltration of the liver which has become refractory to systemic treatment [35]. Outcomes for PLRT, which is usually a non-targeted therapy, were better than for WLRT but not lasting. The 6-month actuarial LC of $62 \%$ for PLRT is, however, far below the most recent LC rates recorded for SBRT [36].

Compared to WLRT and PLRT, SBRT has the advantage of delivering higher tumoricidal doses to the target and sparing uninvolved liver and surrounding critical organs, thus diminishing the likelihood of RILD. SBRT provides more accurate radiation delivery, meets the normal tissue constraints better (Table 3) [37,38], and 
Table 3 Recommended dose constraints to the liver

\begin{tabular}{lll}
\hline Whole-liver RT (WLRT) & Partial liver RT (PLRT) & Stereotactic body radiation RT (SBRT) \\
\hline$\leq 30$ Gy, 2 Gy/fraction & $<32$ Gy, 2-Gy/fraction & $<15$ Gy in 3 fractions \\
21 Gy in 7 fractions & At least 10\% of normal liver spared from radiation & $<20$ Gy in 6 fractions \\
& & $\geq 700 \mathrm{~mL}$ of normal liver receives $\leq 15 \mathrm{~Gy}$ \\
& & 3 to 5 fractions \\
\hline
\end{tabular}

has a smaller PTV margin. The initial LC rate for SBRT of liver metastases was 80\% back in 1995 [39]. However, the latest reports withbetter patient selection show higher efficacy and lower toxicity as well as improved outcomes from advances in multimodality-imaging.

\section{Patient selection}

Strict selection of patients is required to limit normal tissue toxicity to intra-abdominal organs including the liver, stomach, and duodenum. For inclusion in our systematic review, patients had to present no more than 3 metastases; no lesion $>6 \mathrm{~cm}$; no lesion immediately adjacent to the GI tract (distance $>6 \mathrm{~mm}$ ) in radiosurgery patients; and adequate pre-treatment baseline liver function. The RT regimen had to be $\leq 5$ fractions of radiation, with $\geq 700 \mathrm{~mL}$ of normal liver receiving $\leq 15$ Gy (for 3 fractions) or at least $700 \mathrm{~mL}$ for a cumulative dose of 21 Gy (for 5 fractions). GTV was expanded by 5$10 \mathrm{~mm}$ to yield the PTV. These criteria for radiation dose, however, are not derive from validated guidelines but are suggestions based on radiobiological modelling or expert opinion.

On applying these selection criteria, we retrieved 10 prospective studies with a wide variety of doses and schedules (Table 4) [40-49]. The highest total dose per fraction was $60 \mathrm{~Gy}$. The number of fractions was usually
3 (range, 1 to 5). Centrally located lesions might require delivery of the highest number of fractions because of the proximity of critical structures [49].

\section{Local control and follow-up}

Dose escalation, tested by 4 institutions, was associated with improved LC and median survival rates. For liver SBRT as for lung SBRT, a higher radiation dose and a smaller GTV were significant predictors of better LC in univariate analyses. The 3-year actuarial LC rate was $89.3 \%$ for a nominal dose of $\geq 54$ Gy compared to $59.0 \%$ for a 36-53.9 Gy dose and 8.1\% for a $<36$ Gy dose [50]. Among the 10 selected trials in Table 4, doses $\geq 54$ Gy were administered in 2 trials. Kavanagh et al. recorded LC rates of $100 \%$ and $93 \%$ at 1 and 2 years in 36 patients with liver metastases receiving $60 \mathrm{~Gy}$ in 3 fractions. Rule et al. observed excellent LC in their 60-Gy cohort, with no failures at 1 or 2 years. Poorer LC was recorded in trials using doses $<36$ Gy (3 fractions) or 20 Gy (radiosurgery) $[40,42]$. Poorer LC was associated with a greater GTV. The 2-year LC rate was $100 \%$ for $\leq 3 \mathrm{~cm}$ lesions compared to $77 \%$ for $>3 \mathrm{~cm}$ lesions $(\mathrm{P}=0.015$, log-rank test) [47]. In a study of 293 lesions, multivariate analysis revealed a significant association between colorectal metastases and multiple local failure [46], but prior chemotherapy might account for this unconfirmed observation

Table 4 SBRT of liver oligometastases

\begin{tabular}{|c|c|c|c|c|c|}
\hline & \multirow{2}{*}{$\begin{array}{l}\text { Liver metastases } \\
\text { (N) }\end{array}$} & \multirow[t]{2}{*}{ Dose (Gy × fr) } & \multirow{2}{*}{$\begin{array}{l}\text { Median follow } \\
\text { up (mos) }\end{array}$} & \multicolumn{2}{|c|}{ Actuarial LC rate (\%) } \\
\hline & & & & at $12 \mathrm{mos}$ & at $24 \mathrm{mos}$ \\
\hline Herfarth et al. 2001 [40] & 56 & $14-26 \times 1$ & 6 & 75 & \\
\hline Wulf et al. 2001 [41] & 23 & $30 \times 3$ & 9 & 76 & 61 \\
\hline Wulf et al. 2006 [42]. & 51 & variable dose $\times(1-3)$ & 15 & 92 & 66 \\
\hline Hoyer et al. 2006 [43] & 97/141*lesions & $45 \times 3$ & 4.3 years & & 79 \\
\hline Méndez-Romero et al. 2006 [44] & 34 & $37.5 \times 3$ & 13 & 100 & 86 \\
\hline Kavanagh et al. 2006 [45]. & 36 & $60 \times 3$ & 19 & 93 (at 18 mos) & \\
\hline Milano et al. 2008 [46]. & 120/293*lesions & $50 \times 5$ & 41 & & 67 \\
\hline Rusthoven et al. 2009 [47]. & 63 & $36-60 \times 3$ & 16 & 95 & 92 \\
\hline Van der Pool et al. 2010 [48] & 31 & $37.5-45 \times 3$ & 26 & 100 & 74 \\
\hline \multirow[t]{3}{*}{ Rule et al. 2010 [49]. } & 37 & $30 \times 3$ & 20 & & 56 \\
\hline & & $50 \times 5$ & & & 89 \\
\hline & & $60 \times 5$ & & & 100 \\
\hline
\end{tabular}

LC: local control.

* Ratio of liver oligometastases to total number of oligometastases. 
[49]. Overall, the foregoing findings suggest that patients with oligometastases $\leq 3 \mathrm{~cm}$ and who receive doses of 60 Gy might be most likely to achieve long-term control.

Follow-up of patients after liver SBRT is a challenge as the early treatment response (before 3 months) may be difficult to interpret on CT or MRI images because of a reaction to radiation. This reaction may be a form of veno-occlusive disease but is not associated with changes in overall liver function. Changes in contrast enhanced CT-scans were observed in all 44 patients of the Wulf et al. study after fractionated treatment with a cumulative 20 Gy-isodose [42].

LC after SBRT of liver oligometastases is sustained. A median time to maximal response of 6 months and a 71\% LC rate (95\% confidence intervals, 58-85) were reported in a Phase I study of 68 patients receiving 41.8 Gy (range, 27.7 to 60 Gy) [42]. A PET scan obtained at 13 months post-SBRT in an interim analysis of a Phase II study revealed marked uptake in the treated lesion [45].

\section{Toxicity}

Most investigators have evaluated the toxicity of SBRT for liver oligometastases using the Common Terminology Criteria for Adverse Events (CTCAE v3.0). Three cases of fatal toxicity were recorded by the pioneers of liver SBRT in patients with large hepatocellular carcinomas and pre-existing liver disease (ascites, jaundice, cirrhosis, or hepatitis C) [3]. No SBRT-related deaths were reported in the studies we reviewed. In a study of 141 lesions with metastatic colorectal cancer including 69\% with liver oligometastases, there was a death from liver failure in a patient receiving $>10$ Gy to $60 \%$ of the liver (median: 14.4 Gy) and a colon perforation warranting surgery [43].

Serious late SBRT-related complications are not uncommon. Late signs of liver fibrosis, portal hypertension, ascites and bleeding from oesophageal vertices have been described 28 and 41 months after irradiation of two targets close to the liver hilum [42]. A patient with a late episode of ascites (Grade 2) developed a portal hypertension syndrome with melena (Grade 3) [44]. Other possible late sequels have been a case of thoracic pain after irradiation of targets very close to the thoracic wall and a case of rib fracture 10 months after irradiation of a subcapsular liver metastasis located in the vicinity of the ribs $[42,48]$. Early complications reported by Mendéz et al. within 3 months of liver SBRT were elevated gamma-glutamyltransferase (Grade 3) in 3 patients, asthenia (Grade 3) and liver toxicity (Grade 2) in a previously treated patient (chemotherapy and resection) [44]. Ulcers and perforations were noted after delivery of $>30$ Gy in 3 fractions to the intestine [43]. Grade 3 gastritis and skin toxicity (oedema and breakdown) have also been reported [45]. Less serious adverse effects ranged from $29 \%$ in one study (Grade 1 or 2 fever, chills or pain, nausea and vomiting) to $38 \%$ in another (intermittent appetite or mild nausea, moderate singulatus, and fever) $[40,42]$.

\section{SBRT of abdominal lymph node metastases (Local control and toxicity)}

The rationale of administering abdominal SBRT with curative intent to patients with limited nodal metastatic disease is the same as for selected patients with liver or lung metastases. In the case of a single abdominal node, it has been suggested that elective SBRT should incorporate abdominal nodal chains and boosting pathological nodes. This is because a common pattern of relapse of abdominal lymph node (LN) metastases would seem to be within adjacent LNs [51]. Incorporating adjacent retroperitoneal (RP) LNs in the absence of concurrent distant progression was based on the observation that, whereas 6 of 11 patients with 22 oligometastases (19 abdomino-pelvic LNs) treated by hypofractionated IGRT progressed in new para-aortic/RP LNs outside the PTV, first failure in the other 5 patients included adjacent RP LNs at/near midline within 1-2 vertebral bodies of the treated LNs [52]. In this study, Grade 3 GI bleeding occurred in a patient with 3 periduodenal LNs receiving $3 \times 8$ Gy.

Six studies have investigated SBRT of abdominal LN oligometastases in a total of 118 inoperable patients with a variety of primary lesions (Table 5) [51,53-57]. There is no consensus on optimal dose, number of fractions, or planning constraints. The highest dose was $60 \mathrm{~Gy}$; the number of fractions ranged from 3 to 6 . Median followup was 12-28 months. PET-CT was used in 3 studies. Organ motion was minimised with a vacuum pillow or abdominal compression. In the largest study (41 patients), Bae et al. reported PFS, LC and OS rates for 18 colorectal cancer patients with $\mathrm{LN}$ metastases treated by SBRT (45-51 Gy in 3 fractions) (Cyberknife ${ }^{\mathrm{TM}}$ ) and followed up for a median of 28 months (range, 6-65) [51]. Three-year rates were $40 \%, 64 \%$ and $60 \%$ respectively, and 5-year rates were $40,57 \%$ and $38 \%$, respectively.

A GTV of $\leq 17 \mathrm{ml}$ and early radiological response and were favourable predictive factors for LC. The 4-year LC rate was significantly higher for complete responders vs poor responders or non-responders $(90 \%$ vs $24 \%$, $\mathrm{p}=0.014)$ and in patients with a GTV of $\leq 17 \mathrm{~mL}$ $(P=0.0059)[51,55]$. In a univariate analysis, the number of metastases was the only significant prognostic factor identified for 2-year PFS) (41.7\% (solitary) vs 0\% (nonsolitary), $\mathrm{p}<0.0004$ ) [54].

In all 6 studies, three patients experienced serious adverse effects (Grade 3 perforation after pelvic LN SBRT (51 Gy) needing colostomy; 2 patients had Grade 4 intestinal obstruction of para-aortic LN SBRT (48 Gy) 
Table 5 SBRT of abdominal lymph node oligometastases

\begin{tabular}{|c|c|c|c|c|c|}
\hline & Patients (N) & Primary cancer & Dose $(G y) \times f r$ & $\begin{array}{l}\text { Median } \\
\text { follow up (mos) }\end{array}$ & Outcomes \\
\hline \multirow{3}{*}{$\begin{array}{l}\text { Jereczek-Fossa } \\
\text { et al. } 2009 \text { [53] }\end{array}$} & \multirow[t]{3}{*}{14} & \multirow[t]{3}{*}{ Prostate } & \multirow[t]{3}{*}{33 (mean) ×3-5 } & \multirow[t]{3}{*}{ Mean 18.6} & - No in-field clinical progression \\
\hline & & & & & $\begin{array}{l}\text { - Distant or regional LN progression } \\
\text { at mean time of } 12.7 \mathrm{mo}\end{array}$ \\
\hline & & & & & $\begin{array}{l}\text { - All patients with relapse had } \\
\text { high-risk disease }\end{array}$ \\
\hline \multirow[t]{2}{*}{ Bignardi et al. 2011 [54] } & \multirow[t]{2}{*}{19} & \multirow[t]{2}{*}{ CRC (5/19) } & \multirow[t]{2}{*}{$45 \times 6$} & \multirow[t]{2}{*}{12} & $\begin{array}{l}\text { Actuarial rate of freedom from local } \\
\text { progression: } 77.8 \pm 13.9 \text { at both } 12 \\
\text { and } 24 \text { mos }\end{array}$ \\
\hline & & & & & Minimal acute and chronic toxicity \\
\hline \multirow[t]{3}{*}{ Choi et al. 2010 [55] } & \multirow[t]{3}{*}{30} & \multirow[t]{3}{*}{ Uterus and cervix } & EBRT: $27-45(n=4$ pts $)$ & \multirow[t]{3}{*}{15} & 4-year LC rate: $67.4 \%$ \\
\hline & & & \multirow[t]{2}{*}{ SBRT: $33-45 \times 3(n=24 \mathrm{pts})$} & & 4-year OS rate: $50.1 \%$ \\
\hline & & & & & (all 30 pts). \\
\hline \multirow[t]{2}{*}{ Kim et al. 2009 [56] } & \multirow[t]{2}{*}{7} & \multirow{2}{*}{$\begin{array}{l}\text { Gastric (salvage } \\
\text { aftersurgery) }\end{array}$} & \multirow[t]{2}{*}{$48($ median $) \times 3$} & \multirow[t]{2}{*}{26} & Complete response: $n=5$ \\
\hline & & & & & Partial response: $\mathrm{n}=2$ \\
\hline \multirow[t]{4}{*}{ Kim et al. 2009 [57] } & \multirow[t]{4}{*}{7} & \multirow[t]{4}{*}{ CRC } & \multirow[t]{4}{*}{ Escalated dose $36-51 \times 3$} & \multirow[t]{4}{*}{26} & Median survival: 37 mos \\
\hline & & & & & 1-year OS: $100 \%$ \\
\hline & & & & & 3-year OS: 71.4\% \\
\hline & & & & & G4: intestinal obstruction in $1 / 7$ patients \\
\hline \multirow[t]{4}{*}{ Bae et al. 2012 [51] } & \multirow[t]{4}{*}{41} & \multirow[t]{4}{*}{ CRC } & \multirow[t]{4}{*}{$48(45-60) \times 3$} & \multirow[t]{4}{*}{28} & -PFS, LC and OS rates \\
\hline & & & & & 3 -year rates : 40\%, 64\%, 60\% \\
\hline & & & & & 5 -year rates : 40, 57\%, 38\% \\
\hline & & & & & $\begin{array}{l}\text {-G3 perforation after pelvic LN SBRT;G4 } \\
\text { obstruction of para-aortic LN SBRT }\end{array}$ \\
\hline
\end{tabular}

EBRT: electron beam radiotherapy; CRC: colorectal cancer; LN: lymph node; LC: local control, OS: overall survival, G: grade.

needing small bowel resection). In the second largest study (30 patients), 5 of the 25 patients receiving concomitant chemotherapy developed Grade 3 or higher acute haematologic toxicity during chemotherapy [55]. One of the 30 patients developed a urethral stricture 20 months post-SBRT.

In brief, outcomes after SBRT for abdominal LN metastases were similar to those obtained after surgery. Optimal normal tissue constraints and acceptable toxicity have not yet been established.

\section{SBRT of adrenal gland oligometastases}

Adrenal gland metastases from non-small cell lung carcinoma (NSCLC) are present in 5 to $10 \%$ of patients at initial presentation. Surgical resection is the main treatment option. In a review of 11 studies in a total of 60 lung cancer patients who underwent surgical resection of adrenal metastases, median survival was 14-24 months [58]. In patients with an isolated adrenal metastasis, the 5-year OS rate ranged from 10 to 23\% [59]. However, according to Porte et al., aggressive operative intervention is not indicated in patients with a solitary synchronous contralateral metastasis and operable NSCLC as these metastases are likely to be the first manifestation of disseminateddisease because they develop mainly by the haematogenous route. They prefer restaging 3 months after lung resection instead. If the metastasis is homolateral to the primary lesion, a synchronous complete removal can be performed without any added morbidity or mortality [60]. For metachronous metastases, a minimum 10-month interval between diagnosis and resection of metastases is advocated to ensure that there are no other metastatic sites. Patients with a shorter interval between lung resection and adrenal metastasis diagnosis may be amenable to RT or chemotherapy [61].

Clinical experience relating to SBRT of adrenal metastases is limited. We retrieved 4 retrospective studies in a total of 130 patients with a variety of primary lesions, mostly NSCLC (Table 6) [62-65]. The highest dose was $50 \mathrm{~Gy}$; the number of fractions ranged from 3 to 10. Median follow-up was 9.841 months. The low LC rate, reported by Chawla et al. was due to the inclusion of $16 / 30$ patients who underwent SBRT for palliation or prophylactic palliation of bulky adrenal metastases [62]. On the other hand, the median OS of 23 months reported by Holy 
Table 6 SBRT of adrenal gland metastases

\begin{tabular}{|c|c|c|c|c|}
\hline & Patients (N) & Median dose (Gy) & $\begin{array}{l}\text { Median follow up } \\
\text { (mos) }\end{array}$ & Outcomes \\
\hline \multirow[t]{2}{*}{ Chawla et al., 2009 [62] } & \multirow[t]{2}{*}{30} & \multirow[t]{2}{*}{40 Gy (16-50)/4-10 fractions } & \multirow[t]{2}{*}{9.8} & $\begin{array}{l}\text { At 1-year: survival: } 44 \% \text {, LC: } 55 \% \text {, distant } \\
\text { control rate, } 13 \%\end{array}$ \\
\hline & & & & No late Grade $\geq 2$ toxicity \\
\hline Holy et al., 2011[63] & 18 & 20-40 Gy/5 fractions & 21 & $\begin{array}{l}\text { In } 13 \text { patients with isolated adrenal } \\
\text { metastasis: LC }: 77 \% \text {, OS:23 months }\end{array}$ \\
\hline \multirow[t]{2}{*}{ Casamassima et al., 2012 [64] } & \multirow[t]{2}{*}{48} & \multirow[t]{2}{*}{36 Gy/3 fractions ${ }^{a}$} & \multirow[t]{2}{*}{16.2} & $\begin{array}{l}\text { At } 1 \text { and } 2 \text { years, LC: } 90 \% \text {; OS: } 39.7 \% \\
\text { and } 14.5 \% \text {, resp. }\end{array}$ \\
\hline & & & & 1 case of Grade 2 adrenal insufficiency \\
\hline \multirow[t]{2}{*}{ Scorsetti et al., 2012 [65] } & \multirow[t]{2}{*}{34} & \multirow[t]{2}{*}{$32 \mathrm{~Gy} / 4$ fractions } & \multirow[t]{2}{*}{41} & At 1 and 2 years: LC 66\% and 32\%, resp. \\
\hline & & & & No significant acute and late toxicities \\
\hline
\end{tabular}

${ }^{\mathrm{a}} 70 \%$ isodose, 17.14 Gy per fraction at the isocenter. Eight patients were treated with single-fraction (23 Gy) stereotactic radiosurgery.

et al. for patients with an isolated adrenal metastasis is similar to that for surgical resection [63]. According to Casamassima et al., SBRT may be considered as an ablative therapy that is not influenced by factors such as the primary tumour, type of oligometastatic adrenal disease (synchronous vs. metachronous, unilateral vs bilateral) and PTV. Treatments were generally well tolerated. Definitive end-points for toxicity have not been established. A case of Grade 2 adrenal insufficiency was reported by Casamassara et al. [64].

A retrospective comparison by matched case-control study, of surgery (laparoscopic adrenalectomy) versus SBRT (36 Gy in 5 fractions) of an isolated adrenal oligometastases in patients with controlled primary tumours revealed no significant difference in survival at 6 months and 1 year (77\% (95\% CI: 49-100) and 62\% (26-97), respectively, for SBRT and 87\% (75-98) and $77 \%$ (64-91) for LA) [66]. However, these findings need to be confirmed in a prospective study with longer term follow up.

In conclusion, SBRT may be an alternative to surgical resection, especially for solitary adrenal metastases, and displays a low toxicity profile. However, because toxicity occurs late, close attention needs to be paid to the length and quality of follow-up.

\section{Looking ahead}

Until fairly recently, RT of metastases was considered to be palliative only. The above recent advances in imaging and biological targeting, however, provide support for SBRT with curative intent in an oligometastatic setting although, as yet, there is no consensus on schedule (optimal doses, number of fractions, and treatment delivery accuracy). The efficacy of SBRT is well established for liver oligometastases but less well established, although promising, for abdominal LN metastases (one 5-year study) and adrenal gland oligometastases (survival similar to surgical resection for solitary adrenal metastases). Further prospective studies are needed to confirm these results.

SBRT is more effective in the case of "de novo oligometastases" than widespread metastases. A state of "induced oligometastases" needs effective systemic therapy to eradicate most metastatic sites. Emphasis should therefore be placed on the criteria needed for effective patient selection and on delivery of appropriate therapy. Approaches such as microRNA detection have shown promise in patient selection.

Distant metastases are the main cause of death after SBRT. Chemoradiotherapy thus deserves study. Chemotherapy increases organ sensitivity to radiation and also kills tumour cells disseminated in the blood. Promising antitumour responses without potentiation of RT toxicity were observed in a Phase I study of concurrent sunitinib and hypofractionated IGRT followed by maintenance sunitinib in patients with oligometastases [67]. A multi-institutional Phase II trial is ongoing. In 2007, we initiated a Phase II prospective multicentre study of SBRT and concurrent irinotecan in colorectal cancer patients with unresectable liver and lung metastases. As preliminary results for the combination did not differ significantly from those for SBRT alone, we increased the tumoricidal dose in order to achieve higher LC [68]. The study is ongoing.

In conclusion, published studies suggest that SBRT is a valuable alternative to surgery in patients with liver or abdominal lymph node oligometastases although no SBRT standards have yet been defined for the latter. The value of SBRT in the treatment of adrenal oligometastases will depend on their early detection. Future attempts to improve outcomes could focus on including a SBRT plus chemotherapy arm in SBRT trials and identifying patients with oligometastatic disease by microRNA expression. 


\section{Competing interests}

The authors declare that they have no competing interests.

\section{Authors' contributions}

$\mathrm{RE}$ is responsible for the version submitted for publication. MMA planned the structure of the article and critically read the manuscript. SS and PF critically read the manuscript and wrote the section on the biology of hypofractionated SBRT and oligometastases. AMY performed the critical review of the literature and drafted the manuscript. All authors read and approved the final manuscript.

\section{Author details}

'Department of Radiation Oncology, Integrated Oncology Centre, BD du Professeur Jacques MONOD, 44805, Saint-Herblain, France. ${ }^{2}$ INSERM UMR, Nantes-Angers Oncology Research Centre, 8 Quai Moncousu, BP 7072144007, Nantes cédex 1, France.

Received: 10 February 2012 Accepted: 2 July 2012

Published: 1 August 2012

\section{References}

1. Kavanagh BD, McGarry RC, Timmerman RD: Extracranial radiosurgery (stereotactic body radiation therapy) for oligometastases. Semin Radiat Oncol 2006, 16:77-84.

2. Podgorsak EB, Pace GB, Olivier A, Pla M, Souhami M: Radiosurgery with high energy photon beams: A comparison among techniques. Int J Radiat Oncol Biol Phys 1989, 16:857-885.

3. Lax I, Blomgren H, Näslund I, Svanström R: Stereotactic radiotherapy of malignancies in the abdomen. Methodological aspects. Acta Oncol 1994 33:677-683

4. Uematsu M, Shioda A, Tahara K, et al: Focal, high dose, and fractionated modified stereotactic radiation therapy for lung carcinoma patients: a preliminary experience. Cancer 1998, 82:1062-1070.

5. Benedict SH, Yenice KM, Followill D, et al: Stereotactic Body Radiation Therapy: The Report of AAPM Task Group 101. Med Phys 2010, 37:40784101.

6. Hellman S, Weichselbaum RR: Oligometastases. J Clin Oncol 1995, 13:810.

7. MacDermed DM, Weichselbaum RR, Salama JK: A rationale for the targeted treatment of oligometastases with radiotherapy. J Surg Oncol 2008, 98:202-206.

8. Brenner DJ: The linear-quadratic model is an appropriate methodology for determining isoeffective doses at large doses per fraction. Semin Radiat Oncol 2008, 18:234-239.

9. Wolbarst $A B$, Chin LM, Svensson GK: Optimization of radiation therapy: Integral-response of a model biological system. Int J Radiat Oncol Biol Phys 1982, 8:1761-1769.

10. Yeas RJ, Kalend A: Local stem cell depletion model for radiation myelitis. Int J Radiat Oncol Biol Phys 1988, 14:1247-1259.

11. Corre I, Niaudet C, Paris F: Plasma membrane signaling induced by ionizing radiation. Mutat Res 2010, 704:61-67.

12. Fuks Z, Persaud RS, Alfieri A, et al: Basic fibroblast growth factor protects endothelial cells against radiation-induced programmed cell death in vitro and in vivo. Cancer Res 1994, 54:2582-2590.

13. Lee $Y$, Auh $S L$, Wang $Y$, Burnette $B$, et al: Therapeutic effects of ablative radiation on local tumor require $\mathrm{CD} 8+\mathrm{T}$ cells: changing strategies for cancer treatment. Blood 2009, 114:589-595.

14. Lussier YA, Xing HR, Salama JK, et al: MicroRNA expression characterizes oligometastasis(es). PLoS One 2011, 6(12):e28650. Epub 2011 Dec 13.

15. Yin FF, Das S, Kirkpatrick J, et al: Physics and imaging for targeting of oligometastases. Semin Radiat Oncol 2006, 16:85-101.

16. Potters L, Kavanagh B, Galvin JM, et al: American Society for Therapeutic Radiology and Oncology; American College of Radiology. American Society for Therapeutic Radiology and Oncology (ASTRO) and American College of Radiology (ACR) practice guideline for the performance of stereotactic body radiation therapy. Int J Radiat Oncol Biol Phys 2010, 76:326-732.

17. International Commission on Radiation Units and Measurements: Prescribing, recording, and reporting photon beam therapy. Bethesda: 1993. ICRU report, $\mathrm{N}^{\circ} 50$.
18. International Commission on Radiation Units and Measurements: Prescribing, recording, and reporting photon beam therapy (supplement to ICRU Report $N^{\circ}$ 50). Bethesda: 1999. ICRU Report, Nº2.

19. Ohara K, Okumura T, Akisada M, et al: Irradiation synchronized with respiration gate. Int J Radiat Oncol Biol Phys 1989, 17:853-857.

20. Schefter TE, Kavanagh BD, Timmerman RD, et al: A phase I trial of stereotactic body radiation therapy (SBRT) for liver metastases. Int $\mathrm{J}$ Radiat Oncol Biol Phys 2005, 62:1371-1378.

21. Kataria $T$, Abhishek $A$, Chadha $P$, Janarhan $N$ : Assesment of interfraction set-up uncertainties using $\mathrm{X}$-ray volume imaging $(\mathrm{XVI})$ : $\mathrm{A}$ guide to adequate 3D PTV margins [abstract]. Radiother Oncol 2010, 96(Suppl):s425.

22. Wysocka B, Kassam Z, Lockwood G, et al: Interfraction and respiratory organ motion during conformal radiotherapy in gastric cancer. Int $J$ Radiat Oncol Biol Phys 2010, 77:53-59.

23. Myerson RJ, Garofalo MC, El Naqa I, et al: Elective clinical target volumes for conformal therapy in anorectal cancer: a radiation therapy oncology group consensus panel contouring atlas. Int J Radiat Oncol Biol Phys 2009, 74(3):824-30. Epub 2008 Dec 29.

24. Kim CH, Kim H, Beriwal S: Contouring inguinal and femoral nodes: how much margin is needed around the vessels? [abstract]. Int J Radiat Oncol Biol Phys 2011, 81(Suppl 2):s46.

25. Van Weieringen N, Kamphuis M, Bel A, Hulshof MCCM: Determination of margins for pelvic lymph nodes for treatment of bladder cancer [abstract]. Int J Radiat Oncol Biol Phys 2011, 81(Suppl 2):s449.

26. Play J, Efstathiou JA, Hedgire SS, et al: Mapping patterns of nodal metastases in seminoma: Rethinking the para-aortic field [abstract]. Int J Radiat Oncol Biol Phys 2011, 81(Suppl 2):s44. abstract 88.

27. Naisbit M, Sykes J, Brettle D, Magee D, Thwaites DI: A technique for measuring translation and rotation positioning accuracy of automatic table movments using cone beam CT [abstract]. Radiother Oncol 2010, 96 (Suppl):s523.

28. Ling CC, Humm J, Larson S, et al: Towards multidimensional radiotherapy (MD-CRT): biological imaging and biological conformality. Int J Radiat Oncol Biol Phys 2000, 47:551-560.

29. Aerts HJ, Lambin P, Ruysscher DD: FDG for dose painting: a rational choice. Radiother Oncol 2010, 97:163-164.

30. Fong $Y$, Cohen AM, Fortner JG, et al: Liver resection for colorectal metastases. J Clin Oncol 1997, 15:938-946.

31. Singletary SE, Walsh G, Vauthey JN, et al: A role for curative surgery in the treatment of selected patients with metastatic breast cancer. Oncologist 2003, 8:241-251.

32. Small R, Lubezky N, Ben-Haim M: Current controversies in the surgical management of colorectal cancer metastases to the liver. Isr Med Assoc J 2007, 9:742-747.

33. Phillips R, Karnofsky DA, Hamilton LD, Nickson JJ: Roentgen therapy of hepatic metastases. Am J Roentgenol Radium Ther Nucl Med 1954, 71: 826-834.

34. Topkan E, Onal HC, Yavuz MN: Managing liver metastases with conformal radiation therapy. J Support Oncol 2008, 6(15):9-13.

35. Mendez Romero A, Høyer M: Radiation therapy for liver metastases. CurrOpin Support Palliat Care 2012, 6:97-102.

36. Krishnan S, Lin EH, Gunn GB, et al: Conformal radiotherapy of the dominant liver metastasis: a viable strategy for treatment of unresectable chemotherapy refractory cancer liver metastases. Am J Clin Oncol 2006, 29:562-567.

37. Pan CC, Kavanagh BD, Dawson LA, et al: Radiation-associated liver injury. Int J Radiat Oncol Biol Phys 2010, 76(3 Suppl):S94-100.

38. Dawson LA, McGinn CJ, Normolle D, et al: Escalated focal liver radiation and concurrent hepatic artery fluorodeoxyuridine for unresectable hepatic malignancies. J Clin Oncol 2000, 18:2210-2218.

39. Blomgren H, Lax I, Näslund I, Svanström R: Stereotactic high dose fraction radiation therapy of extracranial tumors using an accelerator. Clinical experience of the first thirty-one patients. Acta Oncol 1995, 34:861-870.

40. Herfarth KK, Debus J, Lohr F, et al: Stereotactic single-dose radiation therapy of liver tumors: results of a phase I/II trial. J Clin Oncol 2001, 19:164-170.

41. Wulf J, Hädinger U, Oppitz U, et al: Stereotactic radiotherapy of targets in the lung and liver. Strahlenther Onkol 2001, 177:645-655.

42. Wulf J, Guckenberger M, Haedinger U, et al: Stereotactic radiotherapy of primary liver cancer and hepatic metastases. Acta Oncol 2006, 45: 838-847. 
43. Hoyer M, Roed $\mathrm{H}$, Traberg Hansen A, et al: Phase II study on stereotactic body radiotherapy of colorectal metastases. Acta Oncol 2006, 45:823-830.

44. Méndez Romero A, Wunderink W, Hussain SM, et al: Stereotactic body radiation therapy for primary and metastatic liver tumors: A single institution phase i-ii study. Acta Oncol 2006, 45:831-837.

45. Kavanagh BD, Schefter TE, Cardenes HR, Stieber WW, Raben D, Timmerman $\mathrm{RD}$, et al: Interim analysis of a prospective phase I/II trial of SBRT for liver metastases. Acta Oncol 2006, 45:848-855.

46. Milano MT, Katz AW, Schell MC, Philip A, Okunieff P: Descriptive analysis of oligometastatic lesions treated with curative-intent stereotactic body radiotherapy. Int J Radiat Oncol Biol Phys 2008, 72:1516-1522.

47. Rusthoven KE, Kavanagh BD, Cardenes $\mathrm{H}$, et al: Multi-institutional phase I/II trial of stereotactic body radiation therapy for liver metastases. J Clin Oncol 2009, 27:1572-1578.

48. Van der Pool AE, Méndez Romero A, Wunderink W, et al: Stereotactic body radiation therapy for colorectal liver metastases. Br J Surg 2010, 97:377-382

49. Rule W, Timmerman $R$, Tong $L$, et al: Phase I dose-escalation study of stereotactic body radiotherapy in patients with hepatic metastases. Ann Surg Oncol 2011, 18(4):1081-7. Epub 2010 Nov 3.

50. McCammon R, Schefter TE, Gaspar LE, et al: Observation of a dose-control relationship for lung and liver tumors after stereotactic body radiation therapy. Int J Radiat Oncol Biol Phys 2009, 73:112-118.

51. Bae SH, Kim MS, Cho CK, et al: High dose stereotactic body radiotherapy using three fractions for colorectal oligometastases. J Surg Oncol 2012. doi:10.1002/jso.23058 [Epub ahead of print].

52. Hasselle MD, Salama JK, Tye KE, et al: Patterns of progressive following hypofractionated image-guided radiotherapy (HIGRT) to abdominal lymph nodes in oligometastatic (OM) patients [abstract]. Int J Radiat Oncol Biol Phys 2011, 81(Suppl 2):s654.

53. Jereczek-Fossa BA, Fariselli L, Beltramo G, Catalano G, Serafini F, Garibaldi C, Cambria R, Brait L, Possanzini M, Bianchi LC, Vavassori A, Zerini D, Orsi F, de Cobelli O, Orecchia R: Linac-based or robotic image-guided stereotactic radiotherapy for isolated lymph node recurrent prostate cancer. Radiother Oncol 2009, 93:14-17.

54. Bignardi M, Navarria P, Mancosu P, et al: Clinical outcome of hypofractionated stereotactic radiotherapy for abdominal lymph node metastases. Int J Radiat Oncol Biol Phys 2011, 81(3):831-8. Epub 2010 Aug 26.

55. Choi CW, Cho CK, Yoo SY, et al: Image-guided stereotactic body radiation therapy in patients with isolated para-aortic lymph node metastases from uterine cervical and corpus cancer. Int J Radiat Oncol Biol Phys 2009, 74:147-153.

56. Kim MS, Yoo SY, Cho CK, et al: Stereotactic body radiotherapy for isolated para-aortic lymph node recurrence after curative resection in gastric cancer. J Korean Med Sci 2009, 24:488-492.

57. Kim MS, Cho CK, Yang KM, et al: Stereotactic body radiotherapy for isolated paraaortic lymph node recurrence from colorectal cancer. World J Gastroenterol 2009, 15:6091-6095.

58. Beitler AL, Urschel JD, Velagapudi SR, Takita H: Surgical management of adrenal metastases from lung cancer. J Surg Oncol 1998, 69:54-57.

59. Shen KR, Meyers BF, Larner JM, Jones DR, American College of Chest Physicians: Special treatment issues in lung cancer: ACCP evidence-based clinical practice guidelines (2nd edition). Chest 2007, 132(3 Suppl):290S-305S.

60. Porte HL, Roumilhac D, Graziana JP, et al: Adrenalectomy for a solitary adrenal metastasis from lung cancer. Ann Thorac Surg 1998, 65:331-335.

61. Higashiyama M, Doi O, Kodama K, Yokouchi H, Imaoka S, Koyama H: Surgical treatment of adrenal metastasis following pulmonary resection for lung cancer: comparison of adrenalectomy with palliative therapy. Int Surg 1994, 79:124-135.

62. Chawla S, Chen Y, Katz AW, et al: Stereotactic body radiotherapy for treatment of adrenal metastases. Int J Radiat Oncol Biol Phys 2009, 75:71-75.

63. Holy R, Piroth M, Pinkawa M, Eble MJ: Stereotactic body radiation therapy (SBRT) for treatment of adrenal gland metastases from non-small cell lung cancer. Strahlenther Onkol 2011, 187:245-251

64. Casamassima F, Livi L, Masciullo S, et al: Stereotactic radiotherapy for adrenal gland metastases: university of Florence experience. Int J Radiat Oncol Biol Phys 2012, 82:919-923.

65. Scorsetti M, Alongi F, Filippi AR, et al: Long-term local control achieved after hypofractionated stereotactic body radiotherapy for adrenal gland metastases: A retrospective analysis of 34 patients. Acta Oncol 2012, 51(5):618-623.
66. Arnaud A, Caiazzo R, Claude L, Zerrweck C, Carnaille B, Pattou F, Carrie C: Stereotactic Body radiotherapy vs surgery for treatment of isolated adrenal metastases: A matched pair analysis including 62 patients [abstract]. Int J Radiat Oncol Biol Phys 2011, 81(Suppl 2):s89.

67. Kao J, Packer S, Vu HL, et al: Phase 1 study of concurrent sunitinib and image-guided radiotherapy followed by maintenance sunitinib for patients with oligometastases: acute toxicity and preliminary response. Cancer 2009 Aug 1, 115(15):3571-80.

68. Almaghrabi MY, Rio E, Mahé M, et al: Stereotactic Body Radiation Therapy (SBRT) with concomitant chemotherapy (Campto) for lung and liver metastases of colorectal cancer (CRC): Preliminary results of a prospective Phase II multicenter study [abstract]. Int J Radiat Oncol Biol Phys 2011, 81(Suppl 2):s367.

doi:10.1186/1748-717X-7-126

Cite this article as: Almaghrabi et al:: Stereotactic body radiation therapy for abdominal oligometastases: a biological and clinical review. Radiation Oncology 2012 7:126.

\section{Submit your next manuscript to BioMed Central and take full advantage of:}

- Convenient online submission

- Thorough peer review

- No space constraints or color figure charges

- Immediate publication on acceptance

- Inclusion in PubMed, CAS, Scopus and Google Scholar

- Research which is freely available for redistribution 